\title{
Echocardiography for patients undergoing extracorporeal cardiopulmonary resuscitation: a primer for intensive care physicians
}

Zhongheng Zhange

\begin{abstract}
Echocardiography is an invaluable tool in the management of patients with extracorporeal cardiopulmonary resuscitation (ECPR) and subsequent extracorporeal membrane oxygenation (ECMO) support and weaning. At the very beginning, echocardiography can identify the etiology of cardiac arrest, such as massive pulmonary embolism and cardiac tamponade. Eliminating these culprits saves life and may avoid the initiation of extracorporeal cardiopulmonary resuscitation. If the underlying causes are not identified or intrinsic to the heart (e.g., such as those caused by cardiomyopathy and myocarditis), conventional cardiopulmonary resuscitation (CCPR) will continue to maintain cardiac output. The quality of CCPR can be monitored, and if cardiac output cannot be maintained, early institution of extracorporeal cardiopulmonary resuscitation may be reasonable. Cannulation is sometimes challenging for extracorporeal cardiopulmonary resuscitation patients. Fortunately, with the help of ultrasonography procedures including localization of vessels, selecting a cannula of appropriate size and confirmation of catheter tip may become easy under sophisticated hand. Monitoring of cardiac function and complications during extracorporeal membrane oxygenation support can be done with echocardiography. However, the cardiac parameters should be interpreted with understanding of hemodynamic configuration of extracorporeal membrane oxygenation. Thrombus and blood stasis can be identified with ultrasound, which may prompt mechanical and pharmacological interventions. The final step is extracorporeal membrane oxygenation weaning. A number of studies investigated the accuracy of some echocardiographic parameters in predicting success rate and demonstrated promising results. Parameters and threshold for successful weaning include aortic VTI $\geq 10 \mathrm{~cm}$, LVEF $>20-25 \%$, and lateral mitral annulus peak systolic velocity $>6 \mathrm{~cm} / \mathrm{s}$. However, the effectiveness of echocardiography in ECPR patients cannot be determined in observational studies and requires randomized controlled trials in the future. The contents in this review are well known to echocardiography specialists; thus, it should be used as an educational material for emergency or intensive care physicians. There is a trend that focused echocardiography is performed by intensivists and emergency physicians.
\end{abstract}

Keywords: Echocardiography, Critical care, Extracorporeal cardiopulmonary resuscitation, Cardiac arrest, Thromboembolism

Correspondence: zh_zhang1984@hotmail.com

Department of Emergency Medicine, Sir Run-Run Shaw Hospital, Zhejiang University School of Medicine, No 3, East Qingchun Road, Hangzhou 310016, Zhejiang Province, China 


\section{Background}

Cardiac arrest is one of the most important causes of sudden death in general population. The causes of cardiac arrest include, but are not limited to, ischemic heart disease, trauma, sepsis, cardiac arrhythmia, acute respiratory insufficiency, hypotension, and stroke. The incidence of cardiac arrest is estimated to be 17-53 per million population per year [1-4]. Cardiopulmonary resuscitation (CPR) is the first-line therapy for these patients. In out-of-hospital cardiac arrest (OHCA), the major components of CPR include electronic defibrillation and chest compression, aiming to restore spontaneous circulation [5]. Although prompt and high-quality $\mathrm{CPR}$ is effective in rescuing a portion of cardiac arrest patients, the mortality of conventional CPR (CCPR) is unacceptably high and a significant number of patients require further advanced life support [6]. It has been reported that $44 \%$ of in-hospital cardiac arrest patients had a return of spontaneous circulation, and 17\% survived to hospital discharge. However, if the initial pulseless arrhythmia was ventricular fibrillation, 58\% patients had return of spontaneous circulation and 34\% survived to discharge [6]. Extracorporeal cardiopulmonary resuscitation (ECPR) is considered to be an indispensible modality for those with refractory cardiac pump failure [7]. Extracorporeal membrane oxygenation is always needed after extracorporeal cardiopulmonary resuscitation; thus, we discuss on the use of echocardiography through the entire course of extracorporeal support. There is evidence supporting that extracorporeal cardiopulmonary resuscitation tends to be superior to conventional CPR in improving neurological outcome at 3-6 months in patients with out-of-hospital cardiac arrest (risk ratio, 4.65; 95\% CI, 2-10.81) [8]. The same results have been replicated in pediatric patients and in-hospital cardiac arrest [9]. It is recommended that the time for the decision of extracorporeal membrane oxygenation initiation and extracorporeal membrane oxygenation team activation should be shortened, particularly during the CPR of relatively young patients and in-hospital cardiac arrest (IHCA) patients [10]. In recent years, there is an increase in the use of extracorporeal membrane oxygenation for cardiac support, as well as extracorporeal membrane oxygenation for acute respiratory failure [11]. Therefore, the assessment before initiation of extracorporeal membrane oxygenation and the monitoring during extracorporeal membrane oxygenation performance are of critical importance [12]. Echocardiography provides a non-invasive, radiation-free modality for the assessment of patients undergoing extracorporeal cardiopulmonary resuscitation. There is a trend that focused echocardiography is performed by intensivists and emergency physicians. The concepts of critical care echocardiography indicate that the examination is performed and interpreted by the nonechocardiographer physician as an extension of the physical examination for hemodynamic assessment [13]. The present article aims to provide a comprehensive review of updated evidence on the use of echocardiography for assessment of extracorporeal cardiopulmonary resuscitation.

\section{Echocardiography in identification of pulmonary embolism}

Massive pulmonary embolism is a common cause of cardiac arrest with a reported mortality rate between 20 and $50 \%[14,15]$. Epidemiological study suggested that incidence of pulmonary embolism increased from $0.03 \%$ in 1997 to $0.13 \%$ in 2008 , but its case fatality is decreasing [16] (Fig. 1). This can be partly explained by increased

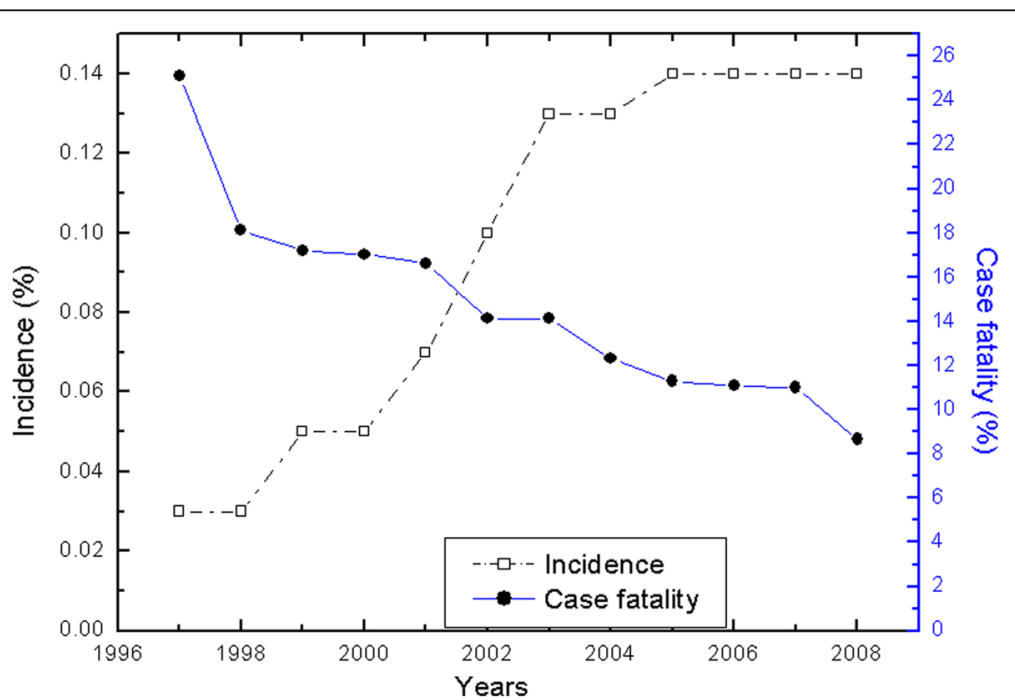

Fig. 1 Incidence of pulmonary embolism increased from $0.03 \%$ in 1997 to $0.13 \%$ in 2008, but the case fatality rates decreased from 25 to $8 \%$ over the years [16]. The figure was reused under the terms of the Creative Commons Attribution License 
awareness of this disease and extensive use of ultrasound for screening. Although there is no high-level evidence that echocardiography improves clinical outcome in cardiac arrest patients caused by pulmonary embolism, there are many case reports suggesting the potential role of echocardiography in management of such patients (Table 1). Focused echocardiography has been recommended for use to identify pulmonary embolism $(\mathrm{PE})$, and the diagnostic performance is desirable $[17,18]$. It is well known that computed tomography pulmonary angiography (CTPA) is the gold standard for the diagnosis of PE. However, the emergency setting of ECPR significantly limits the performance of CTPA. Thus, echocardiography can be the first modality in this particular setting. Typical findings of massive PE include marked dilation of the right heart and the compromised left ventricle (LV) (Fig. 2). Embolism can be noted for large portion of the population. However, in situations with disseminated microvascular embolism, imaging techniques including echocardiography and computed tomography angiography are usually unrevealing. The diagnosis was confirmed with necropsy [19]. These case series suggested that focused echocardiography performed by an emergency physician can be efficient in identifying massive PE, and appropriate interventions can be instituted including thrombolysis, extracorporeal mechanical support, and even the underlying causes of pulmonary embolism [19-26]. However, evidence from the case series is subject to selection bias and thus the diagnostic utility of echocardiography in the condition of extracorporeal cardiopulmonary resuscitation is not well established. We recommend that focused echocardiography be performed in experienced centers.

Beyond the determination of $\mathrm{PE}$, ultrasound monitoring during CPR is able to track the resolution of PE after thrombolytic therapy. Ramarapu reported that transesophageal echocardiography (TEE) monitoring during CPR revealed progressive resolution of the intracardiac, and after $45 \mathrm{~min}$, complete resolution of thrombus was noted [27].

\section{Echocardiography in monitoring effectiveness of CCPR and transition to ECPR}

A challenge in performing extracorporeal membrane oxygenation is the timing of extracorporeal membrane oxygenation initiation. There is some observational evidence that late initiation of extracorporeal membrane oxygenation results in poor neurological and mortality outcomes [28-32]. For example, Chen's study showed that patients who had conventional cardiopulmonary resuscitation for $45 \mathrm{~min}$ or less before extracorporeal cardiopulmonary resuscitation had higher rate of survival

Table 1 Case reports of extracorporeal cardiopulmonary resuscitation caused by pulmonary embolism

\begin{tabular}{|c|c|c|c|c|c|c|}
\hline Cases (authors + year) & Age/gender & Condition & $\begin{array}{l}\text { Type of cardiac } \\
\text { arrest }\end{array}$ & $\begin{array}{l}\text { Who performed } \\
\text { ultrasound }\end{array}$ & Mode & Finding \\
\hline Jeong et al 2015 [20] & 46/female & $\begin{array}{l}\text { Large B cell } \\
\text { lymphoma }\end{array}$ & PEA & $\begin{array}{l}\text { Emergency } \\
\text { physician }\end{array}$ & Transthoracic & $\begin{array}{l}\text { Marked RA dilatation, } \\
\text { a small LV, and abnormal } \\
\text { inter-ventricular septal } \\
\text { wall motion }\end{array}$ \\
\hline Chowdhury et al. 2015 [21] & 63/male & $\begin{array}{l}\text { Abdominal } \\
\text { surgery }\end{array}$ & PEA & Not reported & Transthoracic & $\begin{array}{l}\text { Enlarged RA with multiple } \\
\text { thrombi, compressed LV } \\
\text { with inter-ventricular } \\
\text { septal shift }\end{array}$ \\
\hline Swol et al. 2016 [22] & $\begin{array}{l}5 \text { cases } \\
\text { (37-53 years) }\end{array}$ & Trauma and injury & Not reported & Not reported & Transthoracic & $\begin{array}{l}\text { Thrombus of the inferior } \\
\text { vena cava that extended } \\
\text { to the RV }\end{array}$ \\
\hline Northey et al. 2015 [23] & 34/female & No & Not reported & Not reported & Transthoracic & $\begin{array}{l}\text { Severe RV dilatation with } \\
\text { global systolic impairment } \\
\text { and failure }\end{array}$ \\
\hline Lu et al. 2004 [24] & 73/male & Fracture surgery & Not reported & Not reported & Transesophageal & $\begin{array}{l}\text { Severely distended RA } \\
\text { and RV, with a large } \\
\text { embolus in the RA }\end{array}$ \\
\hline Tsai et al. 1999 [25] & 58/female & $\begin{array}{l}\text { Uterine cervix } \\
\text { carcinoma }\end{array}$ & Not reported & Not reported & Transesophageal & $\begin{array}{l}\text { Marked RA dilation, } \\
\text { a small RV, and nearly } \\
\text { empty chambers of } \\
\text { the left heart, massive } \\
\text { thromboembolism in } \\
\text { the RA }\end{array}$ \\
\hline Ilsaas et al 1998 [26] & 43/female & Cesarean section & Not reported & Not reported & Not reported & $\begin{array}{l}\text { RV dilation, compressed LV } \\
\text { and tricuspid insufficiency }\end{array}$ \\
\hline Liang et al. 2011 [19] & 59/male & NSCLC & Not reported & Not reported & Transthoracic & $\begin{array}{l}\text { Marked RV dilation; } \\
\mathrm{LVEF}=68 \%\end{array}$ \\
\hline
\end{tabular}




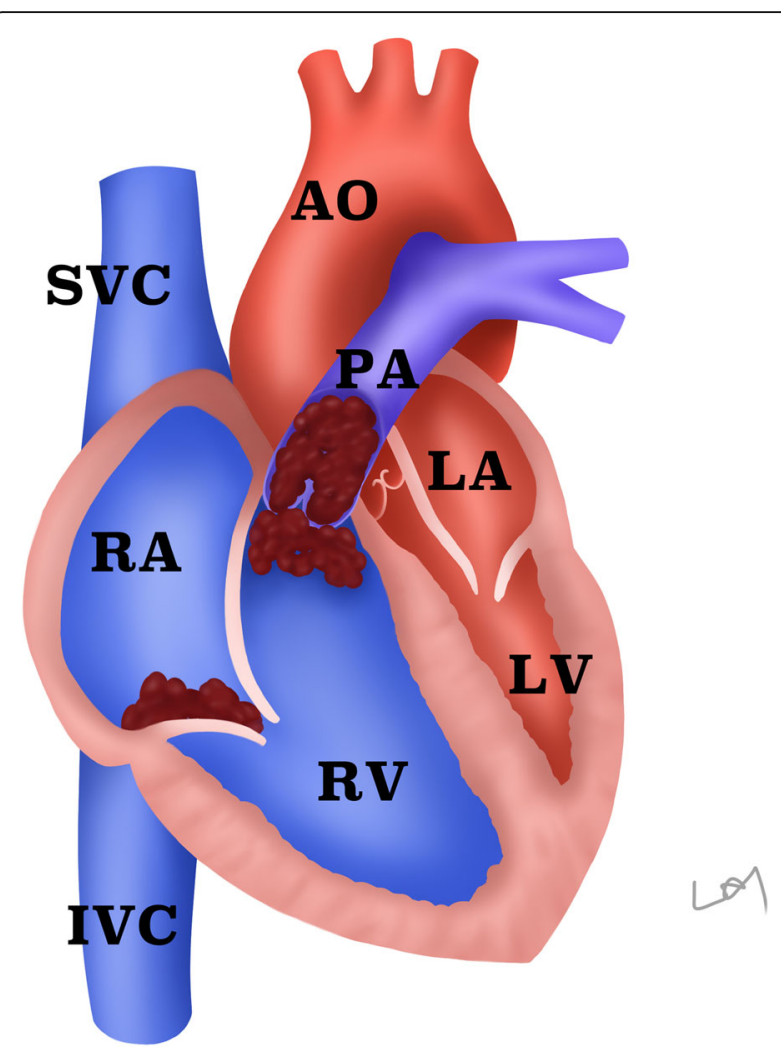

Fig. 2 Morphological changes of the heart in massive pulmonary embolism (PE). Note the dilated right heart and decompressed left heart. PE occludes the main trunk of the pulmonary artery, resulting in marked increase in afterload of the right ventricle. Abbreviations: SVC superior vena cava, IVC inferior vena cava, $R A$ right atrium, $R V$ right ventricle, $L A$ left atrium, $L V$ left ventricle, $A O$ aorta, PA pulmonary artery

to discharge than those who had conventional cardiopulmonary resuscitation greater than $45 \mathrm{~min}$ [32]. The reason may be that conventional cardiopulmonary resuscitation is associated with poor perfusion. There is evidence that even the best-performed chest compression during cardiopulmonary resuscitation provides inadequate cardiac output, ranging from 25 to $40 \%$ of the pre-arrest level [33, 34]. Furthermore, cardiopulmonary resuscitation with chest compression device was also associated with a period of "low-flow". Such low-flow period may dictate the initiation of extracorporeal cardiopulmonary resuscitation [35]. Otherwise, prolonged inadequate tissue perfusion will result in poor clinical outcome. Thus, extracorporeal cardiopulmonary resuscitation that is started too later after cardiac arrest will be futile. On the other hand, initiation of extracorporeal cardiopulmonary resuscitation cannot be too early because a substantial number of patients can have return of spontaneous circulation (ROSC) after a short time of conventional cardiopulmonary resuscitation. These patients can have good clinical outcome, while avoiding catastrophic complications induced by extracorporeal membrane oxygenation.

Therefore, the key issue in transition from conventional cardiopulmonary resuscitation to extracorporeal membrane oxygenation is the identification of inadequate cardiac output. Unfortunately, there is no universal agreement on when to start extracorporeal membrane oxygenation from conventional cardiopulmonary resuscitation. The French guideline recommends initiation of extracorporeal cardiopulmonary resuscitation after 30-min conventional cardiopulmonary resuscitation without spontaneous circulation, and conventional cardiopulmonary resuscitation within $15 \mathrm{~min}$ are considered as the contraindication for extracorporeal cardiopulmonary resuscitation [36]. Kim and colleagues found that good neurological outcome appeared to decrease more sharply in the conventional cardiopulmonary resuscitation than in the extracorporeal cardiopulmonary resuscitation group with prolongation of conventional cardiopulmonary resuscitation duration [37]. The survival rate also showed a similar trend (Fig. 3). There are also other modalities to indicate when to transition to extracorporeal cardiopulmonary resuscitation. For example, end-tidal $\mathrm{CO}_{2}<10 \mathrm{mmHg}$ after $20 \mathrm{~min}$ of CCPR is a good predictor of poor clinical outcome and thus may have potential role in deciding extracorporeal cardiopulmonary resuscitation initiation [38-40]. Other biomarkers include serum lactate, creatinine, phosphorous, $\mathrm{pH}$ value, and neuron-specific enolase [41-44]. Echocardiography may provide an alternative to monitor cardiac output during CCPR. Cardiac low-flow can be visualized using echocardiography [35]. Despite lack of evidence to support the use of echocardiography as a method to determine initiation of extracorporeal cardiopulmonary resuscitation, it is rational that if adequate cardiac output cannot be maintained with CCPR, extracorporeal cardiopulmonary resuscitation should be started as early as possible to avoid further neurological damage.

An interesting sign of echocardiography during cardiopulmonary resuscitation is the duration of cardiac standstill, which was defined as "the total duration of consecutive absence of cardiac motion when periresuscitation echocardiography was performed serially every 2 minutes" [45]. Kim et al.'s study found that patients with and without ROSC had significantly different standstill duration $(2.86 \pm 2.07 \mathrm{~min}$ versus $20.30 \pm 8.42 \mathrm{~min}, p<0.001)$. Cardiac standstill $>10 \mathrm{~min}$ was able to predict non-ROSC with $90 \%$ sensitivity and $100 \%$ specificity. Such a high diagnostic accuracy may help to triage patients into those who require extracorporeal cardiopulmonary resuscitation and those who do not. We propose that if cardiac standstill is persistent for one or two CPR cycle, ROSC is very unlikely within an expected time period and extracorporeal cardiopulmonary 


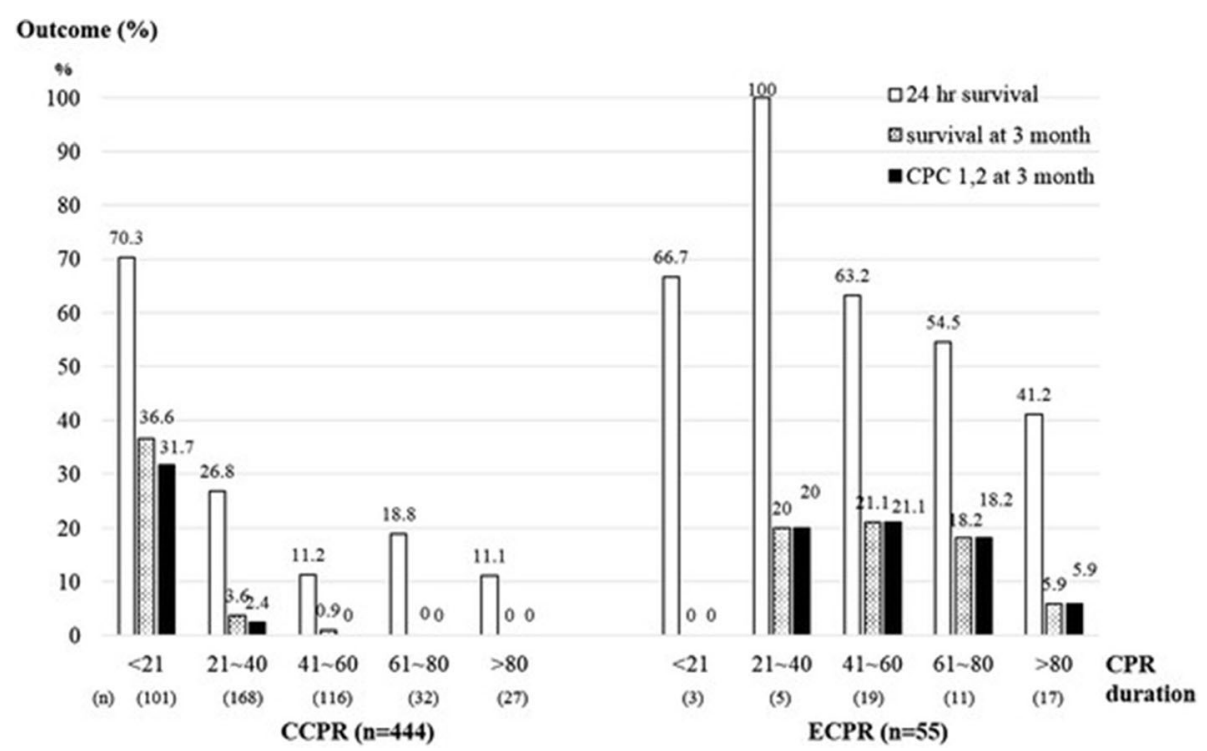

Fig. 3 Twenty-four-hour survival, good neurological outcome, and survival rate at 3 months appeared to decrease more sharply in the CCPR than in the extracorporeal cardiopulmonary resuscitation group with prolongation of CPR duration [37]. The figure was reused under the terms of the Creative Commons Attribution License

resuscitation can be instituted, given that the underlying causes of the cardiac arrest is fully reversible.

The risk of performing echocardiography is the interruption of chest compression, and it is important not to intervene CPR. There have been extensive studies being conducted to explore the performance of echocardiography during CPR [46-48]. The subxiphoid window is the most commonly used because it will not intervene with the ongoing CPR (e.g., the placement of ultrasound probe is outside of the compression region). From this view, it is easy to observe ventricular wall motion, pericardial effusion, and tamponade [49].

\section{Ultrasonography for ECMO cannulation}

Although the primary focus of the article is on echocardiography, here, we include ultrasonography for extracorporeal membrane oxygenation cannulation. For most instances, the cannulation can be performed without the help of ultrasound. However, ultrasound can help to reduce the rate of complications associated with cannulation such as hematoma, vascular injury, cardiac tamponade, and lower leg ischemia [50, 51]. In pediatric patients, the use of ultrasound was associated with significantly reduced rate of surgical repositioning of extracorporeal membrane oxygenation catheter [52].

Before cannulation, the diameter of the target vessels should be localized and measured with ultrasound. Some authors suggest that the diameter of the cannula should be less than two thirds of the diameter of the vessel [50]. Others suggest to choose a cannula that is at least $1-3 \mathrm{~F}$ sizes smaller than the vessel. The size of the cannula can be calculated as follows:

$$
\operatorname{Size}(\mathrm{F})=D(\mathrm{~mm}) \times \mathbf{3}
$$

where $D$ is the diameter of the vessel. If the vessel is distorted by adjacent tissue, the size can be calculated by:

$$
\operatorname{Size}(\mathrm{F})=C(\mathrm{~mm})
$$

where $C$ is the circumference of the distorted vessel. These two equations are very simple for clinical use [53]. The size of the cannula is particularly important for femoral artery because occlusion of it may cause lower extremity ischemia that requires amputation. The cannulation can be performed under real-time ultrasound guidance [54]. The tip position can also be identified by ultrasound, and there is evidence suggesting its superiority to chest radiography [55]. In VA-extracorporeal membrane oxygenation, the tip position of the cannula inserted in the femoral vein is important for reaching a target flow rate. Optimally, the cannula tip should be positioned at proximal inferior vena cava, above the hepatic vein [56] (Fig. 4). After successful cannulation, the heart should be scanned with ultrasound to exclude rare but catastrophic complication tamponade. Furthermore, the distal limb perfusion should be monitored with color-Doplar ultrasound. Percutaneous distal limb perfusion should be instituted in the presence of ischemic signs (Fig. 5) [54]. 

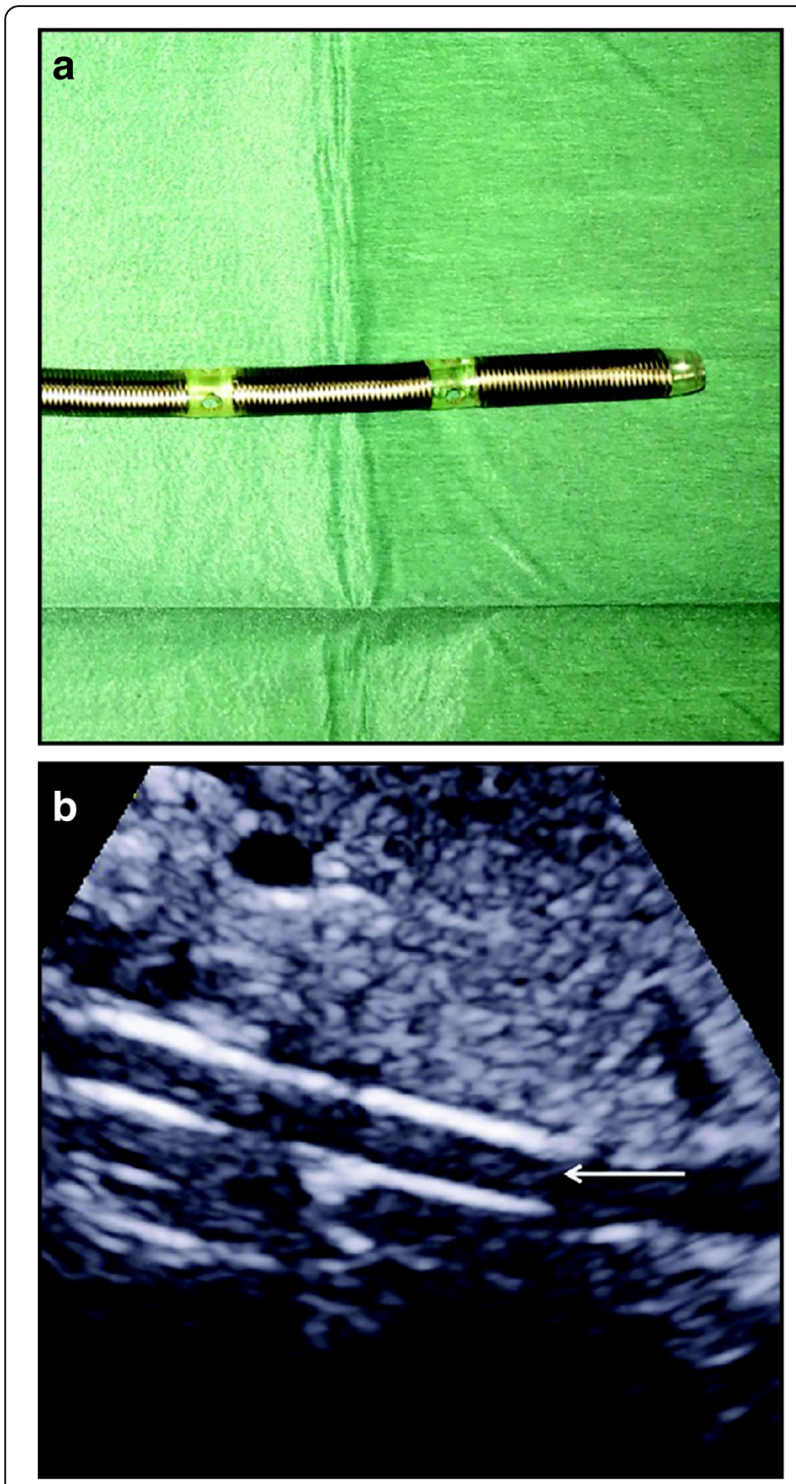

Fig. 4 a Appearance of the access cannula. $\mathbf{b}$ Position of the access cannula was localized in proximal inferior vena cava, above the level of hepatic vein [56]. The figure was reused under the terms of the Creative Commons Attribution License

\section{Monitoring during ECMO performance}

Cardiac function is one of the most important parameters that should be closely monitored during extracorporeal membrane oxygenation support after extracorporeal cardiopulmonary resuscitation. Echocardiography is a useful tool in this regard. Systolic function is assessed with conventional parameters such as the size of the left ventricle (LV), ejection fraction (EF), mitral regurgitation $\mathrm{dP} / \mathrm{dt}$, aortic velocity-time integral (VTI). The extracorporeal membrane oxygenation blood flow rate can be adjusted according to the global assessment of LV systolic function and cardiac preload. Aissaoui and

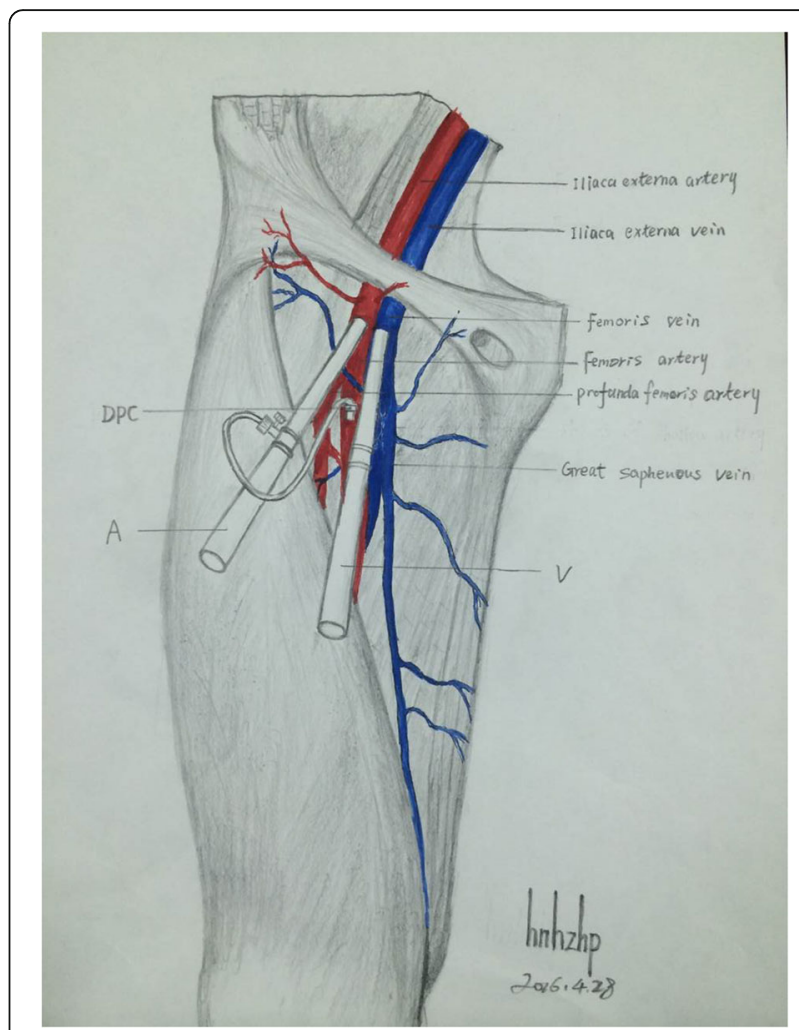

Fig. 5 Schematic illustration of distal limb perfusion to prevent ischemia. $A$ artery, $V$ vein, DPC distal perfusion catheter

colleagues have systematically investigated the effect of extracorporeal membrane oxygenation flow rate on changes in cardiac parameters [57]. A drop in the extracorporeal membrane oxygenation flow rate from 4 to $0.7 \mathrm{~L} / \mathrm{min}$ leads to a $22 \%$ increase in $\mathrm{E} / \mathrm{Ea}$ ratio (5.9 to $7.2 ; p<0.001), 17 \%$ increase in EF (15 to $17.5 \% ; p<0.001$ ), 12 and $45 \%$ increase in VTI ( 8 to $11.6 \mathrm{~cm} ; p<0.001)$, and $12 \%$ increase in left ventricular end-diastolic volume (95 to $108 \mathrm{~mL} ; p<0.001$ ).

Another major issue in using echocardiography is to detect complications during extracorporeal membrane oxygenation running. As described previously, cardiac tamponade can happen when a passage of guide wire or cannula through myocardium. This complication is described in this section because anticoagulation during extracorporeal membrane oxygenation support may worsen pericardial effusion, and tamponade occurs hours or days after cannulation. Therefore, it requires continuous monitoring with echocardiography. What is worse is that conventional signs and symptoms of cardiac tamponade may be of limited use during extracorporeal membrane oxygenation running [58]. Fortunately, these complications can be readily detected using echocardiography [59]. 
Thrombosis is a major complication during extracorporeal membrane oxygenation support and can be catastrophic when embolism occurs in the brain. Many factors predispose the patient at increased risk of blood clotting. The passage of blood through extracorporeal circuit activates clotting cascade, which is compounded by obstruction of intravascular blood flow by the cannula. While evident thrombus is detectable with ultrasound, blood stasis is somewhat challenging to identify. The "spontaneous echo contrast" within cardiac chamber is a sign of blood stasis, which is considered as a harbinger of ensuing thrombosis [60-63]. Closed aortic valve and absence of pulsatile blood flow, which can be easily visualized with echocardiography, are also predictors of thrombosis [64-66]. On seeing this sign, some mechanical or pharmacological efforts could be make to promote forward blood flow. For example, reducing vascular resistance and extracorporeal membrane oxygenation flow rate may allow aortic valve opening and increase forward blood flow. Others recommend the use of intra-aortic balloon pump to facilitate blood flow [67-69]. Alternatively, the anticoagulation strategy can be strengthened.

Aortic and mitral regurgitation is a sign of increased in afterload produced by extracorporeal membrane oxygenation support. Theoretically, the increases in afterload may impair LV distention, ensuing subendocardial ischemia. These are risk factors for delayed recovery of cardiac function [70-72]. However, their clinical utility has been well established in extracorporeal membrane oxygenation setting, and further studies are warranted to clarify their association.

\section{Weaning from ECMO}

The ultimate goal of extracorporeal membrane oxygenation management is to wean from it. Therefore, the prediction of successful weaning has long been an area of active research. Echocardiographic parameters have been shown to be good predictors of extracorporeal membrane oxygenation weaning [73]. If a patient is deemed suitable for weaning, extracorporeal membrane oxygenation weaning trial can be performed by reducing extracorporeal membrane oxygenation flow to less than $1.5 \mathrm{~L} / \mathrm{min}$. Parameters and threshold for successful weaning include aortic VTI $\geq 10 \mathrm{~cm}$, LVEF $>20-25 \%$, and lateral mitral annulus peak systolic velocity $>6 \mathrm{~cm} / \mathrm{s}$ $[56,74,75]$. By applying a standardized weaning protocol [76], Cavarocchi and coworkers developed an extracorporeal membrane oxygenation weaning protocol guided by echocardiography. The ability of ultrasound to detect left and right ventricular dysfunction was good, with a sensitivity of $100 \%$ (95\% CI, 73.2-100\%), specificity of $100 \%$ ( $95 \%$ CI, $56.1-100 \%)$, and positive predictive value of $100 \%$ (95\% CI, 73-100\%) [76]. In pediatric patients undergoing VA-extracorporeal membrane oxygenation for cardiac support, a significant increase $(0.0250 \pm 0.269 \mathrm{~m} ; p=0.03)$ in VTI when extracorporeal membrane oxygenation flow rate was dropped from full support to minimal flow rate was an important predictor of those not requiring a heart transplant [77]. On the contrary, children without significant increase $(0.0111 \pm$ $0.283 \mathrm{~m}$ ) in VTI during weaning trial were subjects that cannot be successfully weaned from extracorporeal membrane oxygenation.

\section{Conclusions}

Echocardiography is an invaluable tool in the management of patients undergoing extracorporeal cardiopulmonary resuscitation and subsequent extracorporeal membrane oxygenation support and weaning. At the very beginning, echocardiography can identify the etiology of cardiac arrest, such as massive PE and cardiac tamponade. Eliminating these culprits saves life and may avoid the initiation of extracorporeal membrane oxygenation. If the underlying causes are not identified or intrinsic to the heart (e.g., such as those caused by cardiomyopathy, myocarditis), CCPR will continue to maintain cardiac output. The quality of CCPR can be monitored and if cardiac output cannot be maintained, early institution of extracorporeal cardiopulmonary resuscitation may be reasonable. Cannulation is sometimes challenging for extracorporeal cardiopulmonary resuscitation patients. Fortunately, with the help of ultrasonography procedures including localization of vessels, selecting a cannula of appropriate size, confirmation of catheter tip may become easy under sophisticated hand. Monitoring of cardiac function and complications during extracorporeal membrane oxygenation support can be done with echocardiography. However, the cardiac parameters should be interpreted with understanding of hemodynamic configuration of extracorporeal membrane oxygenation. Thrombus and blood stasis can be identified with ultrasound, which may prompt mechanical and pharmacological interventions. The final step is extracorporeal membrane oxygenation weaning. Some studies have investigated the accuracy of some echocardiographic parameters in predicting success rate. Although they showed promising results, the effectiveness of echocardiography on CPR survival cannot be determined. Further randomized controlled trials comparing the effects of echocardiographyguided CPR versus conventional CPR may be warranted.

\footnotetext{
Acknowledgements

We would like to thank Ms. Liu Xiaoyang and Dr. Zhiping Huang for providing medical illustrations.
}

Funding

There is no funding for this manuscript.

Availability of data and materials

Data availability is not applicable. 


\section{Competing interests}

The author declares that he has no competing interests.

\section{Consent for publication}

Not applicable.

\section{Ethics approval}

This is a review article and ethics approval is not applicable.

Received: 16 December 2016 Accepted: 26 January 2017

Published online: 02 February 2017

\section{References}

1. Gräsner J-T, Bossaert L. Epidemiology and management of cardiac arrest: what registries are revealing. Best Pract Res Clin Anaesthesiol. Elsevier; 2013;27:293-306

2. Nürnberger A, Sterz F, Malzer R, Warenits A, Girsa M, Stöckl M, et al. Out of hospital cardiac arrest in Vienna: incidence and outcome. Resuscitation. Elsevier; 2013:84:42-7

3. Rossano JW, Naim MY, Nadkarni VM, Berg RA. Epidemiology of pediatric cardiac arrest. pediatric and congenital cardiology, cardiac surgery and intensive care. London: Springer London; 2013. p. 1275-87.

4. De Maio VJ, Osmond MH, Stiell IG, Nadkarni V, Berg R, Cabanas JG. Epidemiology of out-of hospital pediatric cardiac arrest due to trauma. Prehosp Emerg Care. 2011;16:230-6.

5. Travers AH, Perkins GD, Berg RA, Castren M, Considine J, Escalante R, et al. Part 3: adult basic life support and automated external defibrillation: 2015 International Consensus on Cardiopulmonary Resuscitation and Emergency Cardiovascular Care Science With Treatment Recommendations. Circulation. 2015;132(16 Suppl 1):S51-83.

6. Peberdy MA, Kaye W, Ornato JP, Larkin GL, Nadkarni V, Mancini ME, et al. Cardiopulmonary resuscitation of adults in the hospital: a report of 14720 cardiac arrests from the National Registry of Cardiopulmonary Resuscitation. Resuscitation. 2003;58:297-308.

7. Chai PJ, Jacobs JP, Dalton HJ, Costello JM, Cooper DS, Kirsch R, et al. Extracorporeal cardiopulmonary resuscitation for post-operative cardiac arrest: indications, techniques, controversies, and early results-what is known (and unknown). Cardiol Young. 2011;21 Suppl 2:109-17.

8. Kim SJ, Kim HJ, Lee HY, Ahn HS, Lee SW. Comparing extracorporeal cardiopulmonary resuscitation with conventional cardiopulmonary resuscitation: a meta-analysis. Resuscitation. 2016;103:106-16.

9. Lasa JJ, Rogers RS, Localio R, Shults J, Raymond T, Gaies M, et al. Extracorporeal cardiopulmonary resuscitation (E-CPR) during pediatric in-hospital cardiopulmonary arrest is associated with improved survival to discharge: a report from the American Heart Association's Get With The GuidelinesResuscitation (GWTG-R) Registry. Circulation. Lippincott Williams \& Wilkins; 2016:133:165-76

10. Lee S-H, Jung J-S, Lee K-H, Kim H-J, Son H-S, Sun K. Comparison of extracorporeal cardiopulmonary resuscitation with conventional cardiopulmonary resuscitation: is extracorporeal cardiopulmonary resuscitation beneficial? Korean J Thorac Cardiovasc Surg. The Korean Society for Thoracic and Cardiovascular Surgery; 2015:48:318-27

11. Karagiannidis C, Brodie D, Strassmann S, Stoelben E, Philipp A, Bein T, et al. Extracorporeal membrane oxygenation: evolving epidemiology and mortality. Intensive Care Med. 2016;42:889-96.

12. Douflé $G$, Roscoe A, Billia F, Fan E. Echocardiography for adult patients supported with extracorporeal membrane oxygenation. Crit Care. BioMed Central; 2015:19:326

13. Gaspar HA, Morhy SS, Lianza AC, de Carvalho WB, Andrade JL, do Prado RR, et al. Focused cardiac ultrasound: a training course for pediatric intensivists and emergency physicians. BMC Med Ed. BioMed Central; 2014;14:25

14. Kucher N, Rossi E, De Rosa M, Goldhaber SZ. Massive pulmonary embolism. Circulation. Lippincott Williams \& Wilkins; 2006:113:577-82

15. Goldhaber SZ, Visani L, De Rosa M. Acute pulmonary embolism: clinical outcomes in the International Cooperative Pulmonary Embolism Registry (ICOPER). Lancet. 1999;353:1386-9.

16. Yang $Y$, Liang $L$, Zhai $Z$, He $H$, Xie W, Peng $X$, et al. Pulmonary embolism incidence and fatality trends in Chinese hospitals from 1997 to 2008: a multicenter registration study. Cowling BJ, editor. PLOS ONE. Public Library of Science; 2011;6:e26861
17. Labovitz AJ, Noble VE, Bierig M, Goldstein SA, Jones R, Kort S, et al. Focused cardiac ultrasound in the emergent setting: a consensus statement of the American Society of Echocardiography and American College of Emergency Physicians. J Am Soc Echocardiogr. Elsevier; 2010. pp. 1225-30.

18. Squizzato A, Galli L, Gerdes VEA. Point-of-care ultrasound in the diagnosis of pulmonary embolism. Crit Ultrasound J. Springer Milan; 2015;7:7

19. Liang Y-H, Kuo S-W, Lin Y-L, Chang Y-L. Disseminated microvascular pulmonary tumor embolism from non-small cell lung cancer leading to pulmonary hypertension followed by sudden cardiac arrest. Lung Cancer. Elsevier; 2011;72:132-5

20. Jeong WJ, Lee JW, Yoo YH, Ryu S, Cho SW, Song KH, et al. Extracorporeal cardiopulmonary resuscitation in bedside echocardiography-diagnosed massive pulmonary embolism. Am J Emerg Med. 2015;33:1545. e1-2.

21. Chowdhury MA, Moza A, Siddiqui NS, Bonnell M, Cooper CJ. Emergent echocardiography and extracorporeal membrane oxygenation: lifesaving in massive pulmonary embolism. Heart Lung. Elsevier; 2015;44:344-6

22. Swol J, Buchwald D, Strauch J, Schildhauer TA. Extracorporeal life support (ECLS) for cardiopulmonary resuscitation (CPR) with pulmonary embolism in surgical patients - a case series. Perfusion. SAGE Publications; 2016;31:54-9

23. Northey LC, Shiraev T, Omari A. Salvage intraosseous thrombolysis and extracorporeal membrane oxygenation for massive pulmonary embolism. J Emerg Trauma Shock. Medknow Publications; 2015;8:55-7

24. Lu C-W, Chen Y-S, Wang M-J. Massive pulmonary embolism after application of an Esmarch bandage. Anesth Analg. 2004;98:1187-9. tableofcontents.

25. Tsai SK, Wang MJ, Ko WJ, Wang SJ. Emergent bedside transesophageal echocardiography in the resuscitation of sudden cardiac arrest after tricuspid inflow obstruction and pulmonary embolism. Anesth Analg. 1999;89:1406-8.

26. Ilsaas C, Husby P, Koller ME, Segadal L, Holst-Larsen H. Cardiac arrest due to massive pulmonary embolism following caesarean section. Successful resuscitation and pulmonary embolectomy. Acta Anaesthesiol Scand. 1998:42:264-6.

27. Ramarapu S. Complete neurological recovery after transesophageal echocardiography-guided diagnosis and management of prolonged cardiopulmonary resuscitation. A A Case Rep. 2015;5:192-4.

28. Mosca M, Weinberg $A$. The need to develop standardized protocols for the timing of extracorporeal membrane oxygenation initiation among adult patients in cardiac arrest: a case study. J Extra Corpor Technol. American Society of Extra-Corporeal Technology; 2014;46:305-9.

29. Krittayaphong $R$, Saengsung $P$, Chawaruechai $T$, Yindeengam $A$, Udompunturak S. Factors predicting outcome of cardiopulmonary resuscitation in a developing country: the Siriraj cardiopulmonary resuscitation registry. J Med Assoc Thai. 2009;92:618-23.

30. Nadkarni VM, Larkin GL, Peberdy MA, Carey SM, Kaye W, Mancini ME, et al First documented rhythm and clinical outcome from in-hospital cardiac arrest among children and adults. JAMA. American Medical Association; 2006:295:50-7

31. Schultz SC, Cullinane DC, Pasquale MD, Magnant C, Evans SR. Predicting in-hospital mortality during cardiopulmonary resuscitation. Resuscitation. 1996;33:13-7.

32. Chen Y-S, Chao A, Yu H-Y, Ko W-J, Wu I-H, Chen RJ-C, et al. Analysis and results of prolonged resuscitation in cardiac arrest patients rescued by extracorporeal membrane oxygenation. J Am Coll Cardiol. 2003;41:197-203.

33. Andreka P, Frenneaux MP. Haemodynamics of cardiac arrest and resuscitation. Curr Opin Crit Care. 2006:12:198-203.

34. Rubertsson S, Grenvik A, Wiklund L. Blood flow and perfusion pressure during open-chest versus closed-chest cardiopulmonary resuscitation in pigs. Crit Care Med. 1995;23:715-25.

35. Giraud R, Siegenthaler N, Schussler O, Kalangos A, Müller H, Bendjelid K, et al. The LUCAS 2 chest compression device is not always efficient: an echographic confirmation. Ann Emerg Med Elsevier. 2015;65:23-6.

36. Conseil français de réanimation cardiopulmonaire, Société française d'anesthésie et de réanimation, Société française de cardiologie, Société française de chirurgie thoracique et cardiovasculaire, Société française de médecine d'urgence, Société française de pédiatrie, et al. Guidelines for indications for the use of extracorporeal life support in refractory cardiac arrest. French Ministry of Health. Ann Fr Anesth Reanim. 2009. pp. 182-90.

37. Kim SJ, Jung J-S, Park JH, Park JS, Hong YS, Lee SW. An optimal transition time to extracorporeal cardiopulmonary resuscitation for predicting good neurological outcome in patients with out-of-hospital cardiac arrest: a propensity-matched study. Crit Care. 2014;18:535. 
38. Levine RL, Wayne MA, Miller CC. End-tidal carbon dioxide and outcome of out-of-hospital cardiac arrest. N. Engl. J. Med. Massachusetts Medical Society; 1997;337:301-6

39. Pantazopoulos C, Xanthos T, Pantazopoulos I, Papalois A, Kouskouni E, lacovidou N. A review of carbon dioxide monitoring during adult cardiopulmonary resuscitation. Heart Lung Circ. Elsevier; 2015;24:1053-61

40. Eckstein M, Hatch L, Malleck J, McClung C, Henderson SO. End-tidal CO2 as a predictor of survival in out-of-hospital cardiac arrest. Prehosp Disaster Med. 2011;26:148-50.

41. Kelly RB, Harrison RE. Outcome predictors of pediatric extracorporeal cardiopulmonary resuscitation. Pediatr Cardiol. 2010;31:626-33.

42. Huang S-C, Wu E-T, Chen Y-S, Chang C-I, Chiu I-S, Wang S-S, et al. Extracorporeal membrane oxygenation rescue for cardiopulmonary resuscitation in pediatric patients. Crit Care Med. 2008;36:1607-13.

43. Kane DA, Thiagarajan RR, Wypij D, Scheurer MA, Fynn-Thompson F, Emani S, et al. Rapid-response extracorporeal membrane oxygenation to support cardiopulmonary resuscitation in children with cardiac disease. Circulation. Lippincott Williams \& Wilkins; 2010;122:S241-8

44. Böttiger BW, Möbes S, Glätzer R, Bauer H, Gries A, Bärtsch P, et al. Astroglial protein S-100 is an early and sensitive marker of hypoxic brain damage and outcome after cardiac arrest in humans. Circulation. 2001;103:2694-8.

45. Kim HB, Suh JY, Choi JH, Cho YS. Can serial focussed echocardiographic evaluation in life support (FEEL) predict resuscitation outcome or termination of resuscitation (TOR)? A pilot study. Resuscitation. Elsevier; 2016;101:21-6

46. Aichinger $G$, Zechner PM, Prause G, Sacherer F, Wildner G, Anderson CL, et al. Cardiac movement identified on prehospital echocardiography predicts outcome in cardiac arrest patients. Prehosp Emerg Care. 2012;16:251-5.

47. Chardoli M, Heidari F, Rabiee H, Sharif-Alhoseini M, Shokoohi H, Rahimi-Movaghar $\mathrm{V}$. Echocardiography integrated ACLS protocol versus conventional cardiopulmonary resuscitation in patients with pulseless electrical activity cardiac arrest. Chin J Traumatol. 2012;15:284-7.

48. Wu J-P, Gu D-Y, Wang S, Zhang Z-J, Zhou J-C, Zhang R-F. Good neurological recovery after rescue thrombolysis of presumed pulmonary embolism despite prior 100 minutes CPR. J Thorac Dis. 2014;6:E289-93.

49. Ozen C, Salcin E, Akoglu H, Onur O, Denizbasi A. Assessment of ventricular wall motion with focused echocardiography during cardiac arrest to predict survival. Turk J Emerg Med. 2016;16:12-6.

50. Burns J, Cooper E, Salt G, Gillon S, Camporota L, Daly K, et al. A retrospective observational review of percutaneous cannulation for extracorporeal membrane oxygenation. ASAIO J. 2016;62(3):325-8.

51. Chung JH, Jung J-S, Son H-S, Lee SH. Transient limb ischaemia during extracorporeal membrane oxygenation: inappropriate venous cannula location. Interact Cardiovasc Thorac Surg. Oxford University Press; 2015;21:694-5

52. Kuenzler KA, Arthur LG, Burchard AE, Lawless ST, Wolfson PJ, Murphy SG. Intraoperative ultrasound reduces ECMO catheter malposition requiring surgical correction. J Pediatr Surg. 2002;37:691-4

53. Conrad SA, Grier LR, Scott LK, Green R, Jordan M. Percutaneous cannulation for extracorporeal membrane oxygenation by intensivists: a retrospective single-institution case series. Crit Care Med. 2015:43:1010-5.

54. Benassi F, Vezzani A, Vignali L, Gherli T. Ultrasound guided femoral cannulation and percutaneous perfusion of the distal limb for VA ECMO. J Card Surg. 2014;29:427-9.

55. Thomas TH, Price R, Ramaciotti C, Thompson M, Megison S, Lemler MS. Echocardiography, not chest radiography, for evaluation of cannula placement during pediatric extracorporeal membrane oxygenation. Pediatr Crit Care Med. 2009;10:56-9.

56. Victor K, Barrett NA, Gillon S, Gowland A, Meadows CIS, loannou N. Critical care echo rounds: extracorporeal membrane oxygenation. Echo Res Pract. BioScientifica; 2015;2:D1-D11

57. Aissaoui N, Guerot E, Combes A, Delouche A, Chastre J, Leprince P, et al. Two-dimensional strain rate and Doppler tissue myocardial velocities: analysis by echocardiography of hemodynamic and functional changes of the failed left ventricle during different degrees of extracorporeal life support. J Am Soc Echocardiogr. 2012;25:632-40.

58. Yates AR, Duffy VL, Clark TD, Hayes D, Tobias JD, McConnell PI, et al. Cardiac tamponade: new technology masking an old nemesis. Ann. Thorac. Surg. Elsevier; 2014;97:1046-8

59. Hirose H, Yamane K, Marhefka G, Cavarocchi N. Right ventricular rupture and tamponade caused by malposition of the Avalon cannula for venovenous extracorporeal membrane oxygenation. J Cardiothorac Surg. BioMed Central; 2012;7:36.
60. Black IW, Hopkins AP, Lee LC, Walsh WF. Left atrial spontaneous echo contrast: a clinical and echocardiographic analysis. J Am Coll Cardiol. 1991;18:398-404.

61. Vincelj J, Sokol I, Jaksić O. Prevalence and clinical significance of left atrial spontaneous echo contrast detected by transesophageal echocardiography. Echocardiography. 2002;19:319-24.

62. Rittoo D, Sutherland GR, Currie P, Starkey IR, Shaw TR. A prospective study of left atrial spontaneous echo contrast and thrombus in 100 consecutive patients referred for balloon dilation of the mitral valve. J Am Soc Echocardiogr. 1994;7:516-27.

63. Ohtaka K, Takahashi Y, Uemura S, Shoji Y, Hayama S, Ichimura T, et al. Blood stasis may cause thrombosis in the left superior pulmonary vein stump after left upper lobectomy. J Cardiothorac Surg. BioMed Central; 2014;9:159.

64. Moubarak G, Weiss N, Leprince P, Luyt C-E. Massive intraventricular thrombus complicating extracorporeal membrane oxygenation support. Can J Cardiol. Pulsus Group; 2008;24:e1.

65. Madershahian N, Weber C, Scherner M, Langebartels G, Slottosch I, Wahlers T. Thrombosis of the aortic root and ascending aorta during extracorporeal membrane oxygenation. Intensive Care Med. Springer Berlin Heidelberg; 2014;40:432-3

66. Ramjee V, Shreenivas S, Rame JE, Kirkpatrick JN, Jagasia D. Complete spontaneous left heart and aortic thromboses on extracorporeal membrane oxygenation support. Echocardiography. 2013;30:E342-3.

67. Petroni T, Harrois A, Amour J, Lebreton G, Brechot N, Tanaka S, et al. Intraaortic balloon pump effects on macrocirculation and microcirculation in cardiogenic shock patients supported by venoarterial extracorporeal membrane oxygenation*. Crit Care Med. 2014;42:2075-82.

68. Vlasselaers D, Desmet M, Desmet L, Meyns B, Dens J. Ventricular unloading with a miniature axial flow pump in combination with extracorporeal membrane oxygenation. Intensive Care Med. Springer-Verlag; 2006;32:329-33

69. Hu W, Liu C, Chen L, Hu W, Lu J, Zhu Y, et al. Combined intraaortic balloon counterpulsation and extracorporeal membrane oxygenation in 2 patients with fulminant myocarditis. Am J Emerg Med. Elsevier; 2015;33:736.e1-4.

70. Tverskaya MS, Sukhoparova W, Karpova W, Raksha AP, Kadyrova MK, Abdulkerimova NZ, et al. Pathomorphology of myocardial circulation: comparative study in increased left or right ventricle afterload. Bull Exp Biol Med. 2008;145:377-81.

71. Becker M, Kramann R, Dohmen G, Lückhoff A, Autschbach R, Kelm M, et al. Impact of left ventricular loading conditions on myocardial deformation parameters: analysis of early and late changes of myocardial deformation parameters after aortic valve replacement. J Am Soc Echocardiogr. Elsevier; 2007:20:681-9

72. Lucas SK, Schaff HV, Flaherty JT, Gott VL, Gardner TJ. The harmful effects of ventricular distention during postischemic reperfusion. Ann Thorac Surg. 1981;32:486-94

73. Platts DG, Sedgwick JF, Burstow DJ, Mullany DV, Fraser JF. The role of echocardiography in the management of patients supported by extracorporeal membrane oxygenation. J Am Soc Echocardiogr. Elsevier; 2012;25:131-41

74. Aissaoui $N$, Luyt C-E, Leprince $P$, Trouillet J-L, Léger P, Pavie A, et al. Predictors of successful extracorporeal membrane oxygenation (ECMO) weaning after assistance for refractory cardiogenic shock. Intensive Care Med. Springer-Verlag; 2011;37:1738-45

75. Aissaoui N, El-Banayosy A, Combes A. How to wean a patient from veno-arterial extracorporeal membrane oxygenation. Intensive Care Med. 2015:41:902-5.

76. Cavarocchi NC, Pitcher HT, Yang Q, Karbowski P, Miessau J, Hastings HM, et al. Weaning of extracorporeal membrane oxygenation using continuous hemodynamic transesophageal echocardiography. J. Thorac. Cardiovasc. Surg. Elsevier; 2013;146:1474-9

77. Punn R, Axelrod DM, Sherman-Levine S, Roth SJ, Tacy TA. Predictors of mortality in pediatric patients on venoarterial extracorporeal membrane oxygenation. Pediatr Crit Care Med. 2014;15:870-7. 